\title{
The Biology of Bone and Ligament Healing
}

By

Jessica A. Cottrell,* Ph.D., Jessica Cardenas Turner, M.S., Treena Livingston Arinzeh, Ph.D., and J. Patrick O'Connor, Ph.D.

*Corresponding Author

Jessica A. Cottrell, Ph.D.

Department of Biological Sciences

Seton Hall University

Email: cottreje@shu.edu

Address: $\quad 400$ South Orange Ave

South Orange, NJ 07101

Jessica Cardenas Turner, M.S.

Department of Biomedical Engineering

New Jersey Institute of Technology

Email: jmc57@njit.edu

Address: $\quad 323$ Martin Luther King Blvd.

Newark, NJ 07102

Treena Livingston Arinzeh, Ph.D.

Department of Biomedical Engineering

New Jersey Institute of Technology

Email: arinzeh@njit.edu

Address: $\quad 323$ Martin Luther King Blvd.

Newark, NJ 07102

J. Patrick O’Connor, Ph.D.

Department of Orthopaedics

Rutgers-New Jersey Medical School

E-mail: oconnojp@njms.rutgers.edu

Address: $\quad$ Medical Sciences Building, room E-659

185 S. Orange Avenue

Newark, NJ 07103

Disclosure Statement: Dr. Arinzeh receives research funding from the Department of Defense, National Science Foundation, National Aeronautics and Space Administration, Musculoskeletal Transplant Foundation, New Jersey Commission on Spinal Cord Research, Christopher L. Moseley Foundation, and Integra Life Sciences, Inc. Dr. O'Connor is an owner of Accelalox Inc. which is developing novel therapies to promote bone regeneration, and receives research funding from the Musculoskeletal Transplant Foundation and the National Institutes of Health. Drs Cottrell and Turner have nothing to disclose. 


\section{Keywords:}

- Bone Fracture Healing

- Tendon and Ligament Healing

- Arthrodesis

- Tissue Regeneration

- Wound Healing

- Charcot's Neuropathy

- Fifth Metatarsal Fractures

\section{Key Points:}

- Bone healing occurs through primary or secondary ossification to restore the functional integrity of the affected bone.

- Charcot's neuropathy and certain fifth metatarsal fractures have poor healing success rates that are exacerbated by specific risk factors and co-morbidities.

- Ligament and tendon healing is not a regenerative process but occurs through a distinct wounding healing process that requires short-term fibrocartilage formation and long-term tissue remodeling to restore function. 


\section{Synopsis}

This review describes the normal healing process for bone, ligaments, and tendons including primary and secondary healing as well as bone to bone fusion. It depicts the important mediators and cell types involved in the inflammatory, reparative, and remodeling stages of each healing process. It also describes the main challenges for clinicians when trying to repair bone, ligament, and tendon with a specific emphasis on Charcot's neuropathy, fifth metatarsal fractures, arthrodesis, as well as tendon sheath and adhesions. Current treatment options and research areas are also reviewed.

\section{A. Introduction}

Foot and ankle function relies on bones, ligaments, and tendons (BLT) for strength, support, and movement. Injuries to these lower extremities occur frequently at work or during sport related activities and still account for over $20 \%$ of all emergency department visits annually. ${ }^{1}$ Foot and ankle injuries are common in patients between $20-60$ years old and frequently include ligament and bone. Trauma care has made advances over the past three decades which has contributed to a steady decline in the rate of ligament injury. Despite these

improvements, the rate of serious bone injury has continued to grow over this same time. ${ }^{1}$ BLT tissues injuries trigger an inflammatory response which stimulates synthesis of cytokines, growth factors, and other mediators to coordinate the normal tissue healing response. When BLT injuries are complex or associated with other co-morbidities and risk factors, mechanical or biochemical intervention is required to help return the injured tissue back to its original strength and function. The normal mechanisms that guide bone, ligament, and tendon healing will be a focus of this article as well as current treatment challenges for these injuries. 


\section{B. The Biology of Bone Healing}

Fractured bone is capable of undergoing repair and regeneration. However, approximately $10 \%$ of fractures result in delayed fracture healing (delayed union), malunion or

nonunion. ${ }^{2}$ In these cases, the patients experience persistent pain and ultimately require medical intervention to promote healing of the fracture. ${ }^{3,4}$ Fracture healing can be classified into primary and secondary healing. Primary healing requires rigid fixation because it can only occur in the complete absence of motion at the fracture site while secondary healing requires minimization of motion (e.g. cast or splint) at the fracture site. Secondary healing benefits from limited motion at the fracture site to promote callus formation that will ultimately lead to internal immobilization of the fracture. The sequence of events that take place during fracture healing and bone development have been extensively studied at the cellular and molecular levels. ${ }^{5-9}$ These findings have increased our level of understanding of bone healing and may further advance surgical and therapeutic strategies for promoting the repair of damaged bone. This section will discuss the biology of different forms of fracture healing, with secondary healing discussed first since it is the most common form of healing, followed by an overview of bone-bone fusions.

\section{Secondary Healing}

Secondary healing involves endochondral ossification, which mediates the stabilization of the injury and restoration of damaged vasculature prior to regeneration of the tissue during the fracture healing process. This fracture healing process can be divided into three-overlapping phases: (1) inflammatory, (2) reparative, and (3) remodeling where intramembranous and endochondral ossification occur during the reparative phases (Figure 1). ${ }^{10}$ Various cellular components are recruited at different stages in response to growth factors and cytokines. The 
inflammatory phase occurs immediately after injury. In humans the inflammatory phase lasts approximately 1 week whereas in mice, the inflammatory phase lasts less than 4 days. ${ }^{11}$ The damaged vasculature and bone marrow facilitates the influx of primitive mesenchymal stem cells (MSCs) into the fracture site. ${ }^{10}$ During hemostasis, platelets release transforming growth factor- $\beta$ (TGF- $\beta$ ) and platelet-derived growth factor (PDGF) for the stimulation and chemotaxis of undifferentiated MSCs and macrophages. Macrophages are initially recruited to remove debris, necrotic tissue and pathogens at the site of injury. A recent study found that the phenotype of callus macrophages changes during the progression of fracture healing and that macrophage depleted mice impairs fracture healing. ${ }^{12}$ Macrophages express fibroblast growth factors 1 and 2 (FGF-1 and FGF-2), interleukin-1 (IL-1), and TGF- $\beta$ during the inflammatory phase that may help promote angiogenesis within the fracture. ${ }^{12}$ MSCs recruited from the exposed bone marrow, periosteum (outer lining) or endosteum (inner lining) differentiate into fibroblasts, chondrocytes, and osteoblasts during the reparative phase. ${ }^{13}$

Both, intramembranous (IM) and endochondral (EC) ossification occur simultaneously during the reparative phase. IM ossification primarily occurs at the peripheral ends of the presumptive callus as precursor cells differentiate into osteoblasts that lay down woven bone ("hard callus"). These osteoblasts express TGF- $\beta$, FGF-1 and FGF-2, insulin-like growth factorI (IGF-I), and bone morphogenetic proteins (BMPs). In contrast, EC ossification requires the formation of cartilaginous intermediate tissue ("soft callus") prior to ossification. Thus, EC occurs within the bulk of the fracture space where vasculature is initially limited. Within the "soft callus", proliferating chondrocytes express TGF- $\beta$, IGF-I, IGF-II, BMP-2, BMP-4, and BMP-7 in association with increased collagen and cartilage matrix synthesis. ${ }^{14}$ Chondrocytes at the IM/EC interface (chondro-osseous junction) transition into hypertrophy while increasing 
their cell volume as they continue to secrete cartilaginous extracellular matrix. Hypertrophy is initiated and regulated by expression of various transcription factors, primarily, Runx2 and Runx3. As chondrocytes reach hypertrophy and begin to undergo non-apoptotic cell death, matrix metalloproteinases (MMP13 and MMP9) are released to degrade collagen type II and aggrecan (cartilage matrix components) while the hypertrophic chondrocytes express IGF-II and synthesize collagen $\mathrm{X} .{ }^{14}$ Additionally, hypertrophy up-regulates the expression of vascular endothelial growth factor (VEGF). Cartilage is highly avascular, thus, the VEGF expression is crucial for vascular invasion necessary for ossification of the cartilage tissue. Along with new blood vessels, osteoclasts, osteoblasts, and bone marrow cells also invade the hypertrophic cartilage tissue from the IM/EC ossification interface. Osteoclasts partially resorb the cartilaginous matrix, while osteoblasts utilize any remaining matrix as a scaffold to deposit bone matrix. Eventually the matrix becomes mineralized, as bone cells begin to deposit hydroxyapatite (inorganic mineral present in bone). ${ }^{10,15}$ Mineralization is highly regulated by the expression of alkaline phosphatase, osteonectin (binds calcium), osteocalcin (hydroxyapatite regulator), TGF- $\beta$ (increases alkaline phosphatase and osteonectin expression), and BMPs 2, 4, 7, and 9 (increase alkaline phosphatase and osteocalcin expression). ${ }^{8}$ IL-6 is produced by osteoblasts to stimulate bone resorption, while IGF-II modulates resorption by osteoclasts. Eventually woven bone replaces the mineralized callus, and the remodeling phase begins. ${ }^{2,10,15-17}$ Remodeling following fracture repair entails the replacement of woven bone with lamellar bone orchestrated by osteoprogenitor stem cells that differentiate into osteoblasts (bone-forming) and osteoclasts (bone-resorption). Osteopontin mediates anchoring of osteoclasts to bone matrix for resorption during remodeling. ${ }^{18}$ Overall, the remodeling phase occurs gradually in response to mechanical loading, and can last up to several years. 


\section{Primary Healing}

Primary bone healing requires rigid fixation at both ends of the fracture to ensure that the fracture site is completely immobilized, which suppresses "callus" formation. In primary bone healing, cells do not form fibrous or cartilaginous tissue within the fracture gap. Instead, the fracture is repaired from woven bone laid down through intramembranous ossification. Two different types of primary bone healing exist, (1) gap healing and (2) contact healing. ${ }^{16,17}$ In gap healing, small fracture gaps are filled with woven bone, which is then remodeled to complete healing. During remodeling, osteoclasts create 'cutting cones', tunnel-like cavities through the bone and are trailed by osteoblasts that form new lamellar bone while reconstructing Haversian canals and osteons. ${ }^{19,20}$ Different from gap healing, contact healing requires the fracture fragments to be rigidly fixed in contact with each other (e.g., bone fusions). Since fracture gaps are absent, osteoclasts initiate the formation of 'cutting cones' and the reconstructions of the Haversian canals and osteons immediately, without the need for woven bone deposition. Primary healing requires rigid fixation while secondary healing benefits from some motion within the microenvironment of the fracture site. ${ }^{16,17,21}$

\section{Bone-Bone Fusions}

Bone or joint fusions (arthrodesis) are performed surgically to relieve severe pain and restore stability at the joint (Figure 2). ${ }^{22,23}$ In bone-bone fusions, the surgeon completely removes the articular cartilage or fibrous tissue covering the end of the bones at the joint to fully expose the underlying bone tissue. These "exposed" surfaces are then compressed and held together by fixation with pins, screws, plates or rods at an optimal position to create the fusion, which will permanently limit the mobility at the joint. ${ }^{24}$ Primary bone healing occurs where the bone surfaces are pressed into contact and held by rigid fixation. Osteoclasts and osteoblasts then 
begin a primary healing response as discussed above. ${ }^{19,20}$ For example, the ankle is a very complex hinged synovial joint consisting of portions of these three bones: the talus, tibia and fibula; its anatomy allows for a wide range of motion (dorsi- and plantar-flexion, eversion and inversion). In ankle arthrodesis, the distal tibia is typically fused to the talus, and in some cases, the fibula is included in the fusion. ${ }^{23}$ Viable candidates for arthrodesis include patients who suffer from developmental defects, post-traumatic osteoarthritis, rheumatoid arthritis, nonunion or poorly healed fractures, necrosis, implant/graft failure, or neuromuscular disorders (ex, postpoliomyelitis). Commonly reported sites for arthrodesis procedures include the ankle, ${ }^{23,25-27}$ wrist, ${ }^{28}$ foot, ${ }^{22,29,30}$ sacroiliac (rarely post-partum),${ }^{31}$ and spine..$^{32-34}$

Autogenous bone grafts are often utilized in arthrodesis, including ankle arthrodesis. Patients can benefit from osteoprogenitor cells within autogenous bone graft to augment the rate of bone fusion and reduce the risk of nonunion. ${ }^{21}$ Different from contact healing, the process of bone graft incorporation in arthrodesis models is similar to secondary fracture healing process where inflammatory, reparative, and remodeling phases are seen. ${ }^{21}$ Spinal arthrodesis with autogenous iliac crest bone graft remains the gold standard to relieve back pain associated with instability of the spine. Approximately 500,000 spinal arthrodesis surgeries occur per year in the United States. ${ }^{33}$ In those joints in which immobility causes severe disability such as the hip, cubitus (elbow) and knee joints, arthrodesis is considered only in selected patients who are not suitable candidates for preferred operative treatments (e.g., total joint replacement) or after nonoperative and preferred operative treatments have failed. ${ }^{35,36}$ In the latter, arthrodesis is generally a salvage procedure.

Complications associated with arthrodesis procedures have been reported and include a 10-60\% rate of adjacent joint deterioration in the long-term, 10-20\% rate of nonunion, and 3- 
$25 \%$ rate of post-operative infection. ${ }^{25}$ Joint replacement (arthroplasty) has become increasingly popular over arthrodesis because it preserves mobility of the joint, diminishes pain significantly and may decrease the risk of arthritis on the neighboring joints from elevated stress as increased stress in neighboring joints is a drawback of arthrodesis. ${ }^{26,37}$ Evidence shows that in 2004, ankle arthrodesis was performed 9.8 more times than total ankle arthroplasty (TAA) and by 2009 ankle arthrodesis was performed 2.3 times more than TAA. ${ }^{26} \mathrm{~A} 4$ year follow-up study comparing ankle arthrodesis to TAA found that patients who underwent ankle arthrodesis reported ankle osteoarthritis scores (AOS) for pain as 51.2 and for disability as 44.5 , while patients post-TAA reported AOS for pain as 26.0 and for disability as 33.2. An AOS score of 0.0 indicates no pain or disability. Although TAA surgery resulted in significant pain relief, $40.5 \%$ of the patients within the TAA group required post-operative surgical intervention during the follow-up period compared to $21.7 \%$ in the arthrodesis group of patients. ${ }^{25}$ Another report found that adjacent joints become arthritic after arthroplasty more than after arthrodesis during a 5-year follow up. ${ }^{27}$ However, in 2014 the American Orthopaedic Foot \& Ankle Society (AOFAS) endorsed TAA surgery as an established operative treatment option for patients with arthritic conditions affecting the ankle joint. ${ }^{38}$ Total joint replacement is not an option for everyone, certain criteria such as young age, high activity, obesity, misalignment, and history of alcohol and drug consumption are considered risk factors for joint replacement surgery as they may lead to premature wear of implants and require several revision surgeries. ${ }^{25,27}$ Overall, both arthrodesis and arthroplasty are widely used today to treat end-stage arthritic joints, and the selected route of operative treatment is specific to the patient depending on health risk factors, clinical history of the patient, the degree of damage, and the specific joint in need of repair. 


\section{Clinical Challenges in Bone Healing}

Bone, ligaments, and tendons provide important functions to the foot and ankle. When these tissues are injured, inflammation occurs followed by a highly ordered and complex process that promotes healing. Many BLT injuries such as ankle sprains and osteochondral lesions (OCLs) can heal within 6-8 weeks with non-operative measures such as immobilization or reduction in strenuous activity. However, impaired BLT healing is frequently encountered in both inpatient and outpatient situations. Impaired BLT healing is associated with risk factors such as extreme of age, estrogen deficiency, smoking, osteoporosis, diabetes mellitus, alcohol abuse, obesity, non-compliance, chronic site infection, deformity, and neuropathy. Impairment of BLT healing can have devastating consequences to the patient and may lead to injury related morbidity and mortality. Poor fifth metatarsal healing and Charcot neuropathic osteoarthropathy $(\mathrm{CN})$ are both clinically challenging conditions that result from impaired BLT healing. Arthrodesis is a common procedure used to resolve many foot and ankle conditions like CN. However, complications with this procedure are frequent in populations with comorbidities and risk factors. The pathogenesis, etiology, and current treatment challenges for fifth metatarsal and Charcot neuropathic osteoarthropathy will be reviewed below.

\section{Fifth Metatarsal Fractures: Epidemiology, Pathogenesis, and Diagnosis}

Stress and damage induced by direct and indirect injuries to the bone are typically healed by the natural bone remodeling process. Direct damage such as high-impact trauma, including motor vehicle accidents or heavy falling objects, can apply a direct force and lead to metatarsal fractures at any location. ${ }^{39}$ In contrast, indirect forces applying torque to the foot can result in fractures of the metatarsal shafts. ${ }^{40}$ Repetitious stress or chronic damage of a metatarsal can overwhelm the normal remodeling process and weaken spots in the bone, leading to the 
development of stress fractures. Metatarsal fractures account for 35\% of all foot fractures and approximately $25 \%$ result from stress fractures of the fifth metatarsal. ${ }^{41-43}$ Unlike normal fractures, stress fractures do not heal by callus formation instead they undergo direct remodeling. ${ }^{44,45}$ Direct remodeling to heal stress fractures is slow and often stress fractures progress to complete fractures which resist healing and often leads to nonunion. ${ }^{44,45}$ Patients with metatarsal fractures typically show signs of antalgic gait, dorsal edema, and ecchymosis. Clinical, neurovascular, physical, and radiographic evaluations are used to diagnose metatarsal fractures. $^{46}$

\section{Fifth Metatarsal Fractures: Anatomical Considerations}

Of the metatarsals, fifth metatarsal fractures are the most common. They account for $68 \%$ of metatarsal fractures in populations between $20-50$ years old. ${ }^{47,48}$ The fifth metatarsal consists of a base, neck, head, the tuberosity, and the diaphysis (shaft). The lateral band of plantar fascia, the peroneus brevis tendon and the peroneus teritus tendon are all soft tissues associated with the fifth metatarsal. ${ }^{49,50}$ The osteology of the fifth metatarsal is curved and the dorsal-plantar cortex is thinner than the medial-lateral cortex. Blood supply around the fifth metatarsal varies. The tuberosity's blood supply comes from multiple metaphyseal vessels and multiple branches of the nutrient artery. The proximal diaphysis, however, receives its blood supply solely from the nutrient artery. ${ }^{51,52}$ Fracture in the proximal diaphysis is more likely to disrupt the blood supply and contributes to high rates of nonunion, delayed union, or re-fracture. ${ }^{53}$ Proximal fifth metatarsal fractures are sometimes classified into three anatomical zones. Zone I is the most proximal and includes the tuberosity. Zone II is the meta-diaphyseal junction and includes the eponym "Jones Fracture" region. Zone III occurs at the proximal diaphysis. Fractures occurring 
in zone I and zone II usually occur from direct and indirect acute damage while fractures in zone III result from pathological stress. ${ }^{54}$

\section{Fifth Metatarsal Fractures: Treatment and Challenges}

For treatment and prognoses reasons, fractures in the fifth metatarsal are classified into types I, II, and III. ${ }^{50}$ Type I fractures involve the tip of tuberosity and have been associated with sport related injuries. These tuberosity avulsion fractures occur during inversions of the foot and ankle while they are in plantar flexion. Studies have shown that both the lateral band of plantar fascia and the peroneus brevis are involved. ${ }^{39,55}$ Type I injuries are usually completely healed within 6 to 8 weeks if the avulsion fracture is nondisplaced. Conservative treatment includes rest, ice, elevation above heart-level, and often a soft Jones dressing with stiff soled shoe, non-weight bearing short leg cast, or removable cam walker. Complications from type I fractures are unusual, although Bigsby et al. recently demonstrated in a prospective study that 25 percent of patients have pain a year after the injury. ${ }^{56}$ This discomfort is typically correlated with displaced fractures that may lead to nonunion. If a nonunion persists some clinicians use pulsed electromagnetic field therapy or external bone stimulators to promote healing. Pulsed electromagnetic field therapy has been effectively used in the management of delayed unions and nonunions of type I fractures while little research has been conducted on the efficacy of other bone stimulators. ${ }^{40,56,57}$

In type I fractures, surgical intervention is necessary if displacement is greater than 3 $\mathrm{mm}$, a step-off of more than 1 to $2 \mathrm{~mm}$ on the articular surface with the cuboid, $30 \%$ of the metatarsal cuboid joint articulation is involved, or if callus formation is not evident by the eighth week after radiographic examination. ${ }^{39,58,59}$ Surgical interventions for fifth metatarsal fractures

vary but include screw fixation, tension banding, and percutaneous pinning. ${ }^{42,55,60-66}$ In one study, 
the effectiveness of percutaneous biocortical screw fixation for displaced intraarticular zone I proximal fifth metatarsals was studied. ${ }^{64}$ The data demonstrated that percutaneous biocortical screw fixation effectively decreased preoperative displacement and allowed for complete healing within 4 to 6 weeks. Biocortical fixation was suggested to be superior to intramedullary fixation because it disperses the load over a greater cortex surface area and offers greater stability.

Type II injuries occur within the junction of the metaphysis and diaphysis and generally result from an acute sports injury. ${ }^{67}$ Unlike type I injuries, type II injuries are not caused by inversion. These fractures are thought to develop when a significant adduction force is applied to the forefoot while the ankle is in plantar flexion. ${ }^{59}$ Stress fractures can also develop in this area and need to be successfully distinguished from an acute injury in order to develop a proper treatment plan for the patient. Clinical presentation, patient history, and radiographic findings need to be carefully examined to differentiate between acute and stress fractures. Initial treatment requires immobilization in a posterior splint, strict non-weight bearing, icing, and elevation of the limb. For most non-displaced, acute fractures conservative treatment is recommended. ${ }^{39,59,67}$ However, acute type II diaphyseal fractures pose several challenges for successful healing. Since it is difficult to distinguish between acute and stress fractures, incorrect diagnosis often leads to improper treatment and results in a high incidence of nonunion. Therefore, it is important to gain a thorough patient history and carefully examine all radiographs to properly diagnose the patient. Also, treatment of acute diaphyseal fractures requires casting and strict nonweight bearing for long periods of time so many patients are non-compliant. Even with proper diagnosis and treatment many acute diaphyseal fractures result in nonunion or re-fracture. ${ }^{59}$ In a study of basketball players carefully diagnosed with acute proximal diaphysis injury, 50\% percent were found unhealed after 12 weeks of conservative treatment. ${ }^{68}$ Impaired vascular 
supply and premature weight bearing are thought to cause poor healing in these injuries. ${ }^{52,53,67} \mathrm{~A}$ 2005 study, compared conservative and surgical treatment of these fractures. ${ }^{69}$ In this study, approximately $50 \%$ of the patients were treated with intramedullary screw fixation followed by immobilization for a period of two weeks. The remaining $50 \%$ of the patients were immobilized in a non-weight bearing, short leg cast for eight weeks, followed by a walking cast, until there was radiographic and clinical evidence on fracture union. Forty-four percent of the conservatively treated group were found to have a visible symptomatic fracture 26 weeks postfracture while only $5 \%$ of the surgically treated group did. Two other articles which reviewed 32 studies showed that surgical intervention generally reduced the risk of nonunion. ${ }^{70,71}$ As a result of these challenges, early surgical fixation and prolonged use of a customized weight-bearing orthosis are reasonable options for treatments. ${ }^{67,72}$

Type III injuries include stress fractures of the fifth metatarsal and result from chronic and repetitive microtrauma. Type III fractures occur less frequently then type I and II fractures, however they have a much higher propensity to develop into a delayed union, nonunion, or refracture. ${ }^{59,73}$ Radiographically they are distinct from acute fractures and have been classified by Torg based on severity. ${ }^{74}$ An early stress fracture displays cortical thickening (Torg I) while older stress fractures have a thicker fracture line (Torg II) or absence of the medullary canal (Torg III). Most type III injuries require surgical fixation (Torg II \& III) instead of conservative treatment (Torg I). ${ }^{75}$ Conservative treatment is advised only for patients with early stress fractures that would like to avoid surgery and do not mind long-term immobilization. Surgical fixation, bone stimulators, bone grafts, and other therapies have been used to manage problematic stress fractures and are similar to the options already discussed for acute metatarsal injuries. Surgical treatment of these fractures has similar challenges and healing outcomes as 
described for type II metatarsal fractures. However, operative treatment still results in prolonged immobilization time. ${ }^{42,54,63-65}$ Current research is focused on improving the surgical methods to reduce the time a patient is prohibited from activities. One study using teriparatide an FDA approved bone stimulator for osteoporosis treatment focused on improving healing outcomes without surgical intervention. ${ }^{42}$ Improvement was seen in two patients with metatarsal stress fracture healing after treatment with teriparatide, vitamin D3, and calcium citrate. However the scope of this study was limited and future studies are warranted. A future study aims to test the efficacy of adding bone marrow stem cells to the surgical site in order to promote better healing outcomes for metatarsal stress fractures. ${ }^{65}$ Continued research on these specific injuries is warranted and could result in improved healing success in patients with type III fractures as well as those suffering from type I and II fractures.

\section{Charcot Neuropathic Osteoarthropathy (CN): Epidemiology, Pathogenesis, and Diagnosis}

Charcot neuropathic osteoarthropathy $(\mathrm{CN})$, commonly known as Charcot's foot, is a condition where acute localized inflammation affects the bones, joints, and soft tissues of the foot and ankle. $\mathrm{CN}$ results from various peripheral neuropathies but is commonly associated with diabetic neuropathy. The precise incidence of $\mathrm{CN}$ is unclear but it was recently estimated to effect $0.08 \%-0.13 \%$ of the population but has a higher incidence in the diabetic community (7.5$9 \%) .{ }^{76-78} \mathrm{CN}$ can be classified in terms of clinical stage, anatomical localization, and the stage of natural history which have been described extensively in the literature. ${ }^{78-81}$ Proper and prompt diagnosis of $\mathrm{CN}$ is important to minimize the risk of osteophyte development, ulceration, infection, deformity, and amputation. Recent studies demonstrate that plain radiographs are insufficient at diagnosing Charcot foot injuries. ${ }^{9,82,83}$ Many studies have shown that advanced imaging such as magnetic resonance images (MRIs) are better at properly diagnosing CN..$^{9,83-90}$ 
$\mathrm{CN}$ 's cause is thought to be multi-factorial resulting from several components such as diabetes, sensory-motor neuropathy, or metabolic abnormalities of the bone. These components contribute to unresolved acute inflammation in a specific ankle or foot region which inflicts varying degrees of bone damage, subluxation, dislocation, and deformity. Midfoot collapse, commonly known as "rocker-bottom" foot, is a classic deformity associated with $\mathrm{CN}$. The pathogenesis or process by which $\mathrm{CN}$ progresses is not well understood, however, two theories have been described. ${ }^{78}$ The neurovascular theory states that an autonomic stimulated vascular reflex causes hyperemia and increased bone resorption which leads to joint destruction and trauma. The neurotraumatic theory suggests that $\mathrm{CN}$ results from peripheral neuropathy which causes sensory loss in the feet. As a result, repetitive strain, pain, and overload are unrecognized in the insensate region which eventually leads to unknown trauma or injury that triggers the development of CN. ${ }^{78,91-94}$

\section{Charcot Neuropathic Osteoarthropathy (CN): Anatomical Considerations}

CN's classification systems have varied over the years, for simplicity this review will use the classical model to describe the stages of this condition. Stage I is the acute phase and is characterized by fragmentation. The midfoot is usually affected and is characterized by swelling and warmth. Some radiographs display osteopenia, periarticular fragmentation, and subluxation of joints but most will seem typically normal. The acute stage is often misdiagnosed as gout, deep vein thrombosis, or soft tissue injury and as a result the disease can progress to Stage II or III. ${ }^{95-98}$ Stage II represents the reparative phase where edema and warmth decrease, bone absorption occurs and bone formation occurs. Stage III is known as the chronic or inactive stage. ${ }^{78-80,99}$ Many of the acute signs such as warmth and redness disappear, but stable 
deformities may develop in the third stage. ${ }^{78-80,99}$ Common deformities to develop include collapse of the plantar arch in the midfoot or a prominent medial aspect of the midfoot. These deformities often result in formation of abnormally high-pressure areas on the foot that become particularly prone to ulceration. ${ }^{78-80,99}$

\section{Charcot Neuropathic Osteoarthropathy (CN): Treatment and Challenges}

It is of utmost importance that $\mathrm{CN}$ be properly diagnosed and treated during the acute stage to prevent further progression of the condition. Conservative treatment is typical in stage I and includes immobilization with a non-removable device such as a total contact cast (TCC) with instructions to be non-weight bearing. Literature exists that suggests that weight-bearing while immobilized does not negatively affect the resolution of acute CN. ${ }^{9,82,83,89,98,100,101}$ The duration of immobilization is dependent upon the extremity and radiographic evidence of ossification at the site but on average it can range between $8-52$ weeks. ${ }^{77,82,84,87,89,95,98}$ Conservative treatment however has its challenges. Prolonged casting and immobilization can lead to complications such as ulceration and patient compliance during prolonged immobilization periods is not easy to guarantee. ${ }^{97,101-104}$ Other orthotic devices are available (removable walking boots, patellar tendon brace) that help increase patient compliance though studies indicate that use of the orthotic devices increases the length of time patients are immobile. ${ }^{98,105,106}$ Surgical intervention during this acute stage has some major risks for wound healing complications and infection. ${ }^{87,98,99,103,107,108}$ Additionally, bone quality is a main concern because $\mathrm{CN}$ is characterized by the pathogenic process of osteoclastic resorption and fragmentation. The bone quality is feared to be suboptimal for proper fixation which could lead to hardware failure, pseudoarthritis, delayed union, or non-unions. ${ }^{98,99,108}$ Therefore, surgery in the acute phase of CN is restricted to patients with severe dislocation or instability, failure of conservative treatment, 
poor vascular supply near the affected limb, patient's with co morbidities, or evidence of an anatomic location breakdown. Early surgical intervention during acute $\mathrm{CN}$ in diabetic patients was found to be effective at increasing arthrodesis without complications. ${ }^{108}$ Stage II is considered a better time for surgical intervention. Surgical intervention is typically completed with an open reduction and internal fixation. ${ }^{82}$ If the process has reached the stage III, arthrodesis is typically more difficult to achieve because an ostectomy needs to be conducted and may result in ulcerations. ${ }^{82,97,102,109}$

Surgical intervention for $\mathrm{CN}$ includes non-locking and locking plate and screw fixation, intramedullary screw or nail fixation, external fixation, internal fixation or a combination of these methods. ${ }^{110-112}$ Surgical method choice is typically dependent upon bone quality. If bone quality is poor, internal fixation may use a superconstruct. ${ }^{113,114}$ that connects affected joints to non-affected joints in order to gain stability. However, this method requires large incisions which increases the risk of infection, soft tissue complications, and disruption to the osseous vascular supply. ${ }^{110}$ Intramedullary screw and nail fixation requires a smaller open approach and thus limits the risks associated with a large incision. Intramedullary fixation also gives the clinician the ability to correct and realign deformed bone with use of guide wires but complications resulting from hardware failure or migration can occur. ${ }^{5,110,113-119}$ External fixation is used with or without internal fixation if a patient is suffering from severe deformity or instability. Most external devices use tensioned wires to stabilize multiple planes and promote inter-fragmentary compression to prevent implant loosing, neutralize stress placed on the foot, and assist in deformity correction. ${ }^{112,120,121}$ Complications resulting from external fixation are more common in diabetic patients and include pin loosening, pin breakage, pin failure, stress fractures, osteomyelitis, and pin tract infections. ${ }^{122}$ 
If surgical correction requires arthrodesis, the use of bone graft and/or adjuvants may be necessary. Autogenic bone is typically preferred but allogenic, synthetic, or combinatorial bone graft substitutes can be used. Autogenic bone graft is typically harvested from the iliac crest, distal tibia, or fibula and is used to fill osseous voids. ${ }^{123-126}$ Disadvantages of autogenic bone use are donor site morbidity, pain, and availability. ${ }^{123}$ Allogenic grafts avoid the disadvantages associated with autogenic bones and reduces the operating time needed to obtain the bone. Other bone graft substitutes such as demineralized bone matrix (DBM), calcium sulfates, and hydroxyapatites are also readily available as alternatives to allogenic grafts. Incorporating orthobiologics, such as bone morphogenetic protein (BMP), bone marrow aspirate, or plateletrich plasma, into the wound or osseous region can enhance healing. ${ }^{82,127,128}$ In a recent study, patients at high risk for surgical failure (immunodeficient, multiple comorbidities, recurrent infections) underwent $\mathrm{CN}$ surgery for deformity correction using allogenic bone graft supplemented with platelet-rich plasma. ${ }^{129}$ Arthrodesis was achieved in $90 \%$ of the patients and that were also infection free at 26 months. Similar favorable outcomes have been achieved with adjunctive treatments such as bisphosphonates, ${ }^{106}$ intranasal calcitonin,,${ }^{130}$ or bone stimulation. ${ }^{57}$

Since $\mathrm{CN}$ can be challenging to diagnosis and treat, it is recommended that advanced imaging be conducted on any patient with peripheral neuropathy, pain and swelling to rule out acute $\mathrm{CN}$. Immobilization appears to be the preferred treatment for acute stage $\mathrm{CN}$ even though some evidence suggest surgery at this stage can improve outcomes. When surgical intervention is necessary, use of orthobiologics or adjuvants appears to increase positive healing outcomes.

\section{Arthrodesis of the Foot \& Ankle}

Fusion of the foot or ankle is typically used as an end-stage procedure to salvage the limb. Patients with certain risk factors such as smoking, diabetes, alcohol abuse, obesity or 
genetic disorders are at greater risk for complications associated with fusion. Surgical techniques to promote fusion are numerous and include use of internal and external fixation. Examples of these methods were discussed above with regards to treating stage II and III Charcot's foot. Complications are common with arthrodesis and include hardware failure, pin migration, infection, delayed-union, nonunion, stress fractures, or cortical hypertrophy. Biological augmentation with osteoconductive or osteoinductive reagents have been the focus of research to increase fusion success. Some studies show promising results with use of osteobiologics such as rhBMP-2 to promote arthrodesis. ${ }^{23,131,132}$ while others note complications such as heterotopic ossification. ${ }^{23,133,134}$ For an extensive review of the challenges involved in arthrodesis, please see Rabinovich et al. and Slater et al. on complex ankle arthrodesis. ${ }^{23,135}$

\section{Biology of Ligament and Tendon Healing}

\section{Ligament and Tendon Healing}

Tendon and ligament ruptures and tears are common injuries. Acute tendon and ligament injuries are often caused by extrinsic traumatic injuries. ${ }^{136}$ However, rapid accelerationdeceleration movements have been associated with acute sports-related tendon injuries. ${ }^{137}$ Chronic degenerative changes in tendons and ligaments also can lead to susceptibility for rupture or tear. ${ }^{138}$ Possible mechanisms leading to chronic degenerative changes in tendon include damage from reactive oxygen species produced in conjunction with load-induced ischemiareperfusion. ${ }^{139}$, strain induced cyclooxygenase expression leading to $\mathrm{PGE}_{2}$ synthesis, inflammation, and matrix metalloproteinase synthesis and accumulated small partial tears that would weaken the overall tensile strength of the tendon. ${ }^{140-143}$ Use of fluoroquinolone antibiotics, such as ciprofloxacin, also has been associated with increased risk of tendon rupture. ${ }^{144,145}$ Cell 
based studies have shown that ciprofloxacin can induce IL-1ß expression that could possible trigger inflammation-related tendon damage, ${ }^{146}$ though others have suggested that IL-1ß may not be involved in tendinopathy. ${ }^{147}$

Treating tendon and ligament injuries is complicated by an incomplete understanding of how tendons and ligaments heal. For instance, there is significant variation in the ability of some ligaments to heal since knee medial collateral ligament injuries are often managed non-surgically during healing while knee anterior cruciate ligament injuries generally undergo surgical repair. ${ }^{148-150}$ The location of the injury may also affect treatment and outcomes, such as management of adhesion formation in injuries involving the tendon sheath or injuries involving the muscle-tendon (myotendinous) junction or the bone-tendon interface (enthesis).

Unlike bone, tendons and ligaments do not heal by tissue regeneration but rather through a typical wound healing process in which the defect is filled with fibrous tissue. Complete or partial disruption of the tendon or ligament leads to a predictable healing pathway that includes an early phase, reparative phase, and a remodeling phase that increases repaired tendon tensile properties. The early phase consists of hematoma formation, inflammation, and initiation of cell proliferation at the injury site. During the reparative phase, proliferating tenocytes from the tendon and epitenon and proliferating cells from surrounding tissues, e.g., the tendon sheath, localize at the injury site and begin to heal the rupture by formation of fibrous tissue that contains a high proportion of type III collagen. This reparative phase can last for weeks during which time the healing tendon remains mechanically weak and subject to re-injury. During the remodeling phase, the fibrous repair tissue becomes less cellular, glycosaminoglycan concentrations decrease, and the proportion of type I collagen increases. Eventually the collagen fibers and tenocytes align with the direction of stress to increase the repaired tendon tensile 
strength. The remodeling phase can last several months. Factors that mediate inflammation, angiogenesis, cell proliferation, and extracellular matrix remodeling appear to be involved in the different phases of healing based upon gene expression studies. However, the mechanisms that coordinate these gene expression events and the necessity of each factor in tendon healing is not well understood.

Recent studies have cataloged patterns of gene expression following tendon or ligament injuries. Using a mouse flexor tendon defect model, Juneja et al. found a rapid increase in in type III collagen expression that peaked between 2 and 3 weeks after surgery. ${ }^{151}$ Interestingly, expression of anti-inflammatory TGF- $\beta_{3}$ increased approximately 6-fold between 7 and 14 days after fracture which would coincide with the transition from the early to reparative phase of healing. Manning et al. found that type III and type I collagen expression was reduced more than 10-fold immediately after canine flexor tendon transection and repair as compared to normal tendon, while inflammatory related gene expression (IL-1ß and COX-2) was elevated. ${ }^{152}$ Manning et al. also observed that after 9 days, type III collagen gene expression had increased suggesting initiation of the reparative phase. More recent gene expression studies have been conducted using human tendon samples collected during surgery. Using microarrays, Brophy et al. analyzed gene expression between anterior-cruciate ligaments that had been torn $<3$ months (acute), between 3 and 12 months (intermediate), or $>12$ months (chronic). ${ }^{153}$ Ends of the torn ligaments were collected during surgical repair and so no intact specimens were available for comparison. Still, the analysis found that genes involved in extracellular matrix reorganization were expressed in the acute samples, while the chronic samples showed reductions in collagen gene expression and an interesting $>30$-fold decline in periostin expression. Chaudhury et al. compared rotator cuff tendons that had been symptomatic for at least 1 year with small $(<3 \mathrm{~cm})$ 
and large $(>3 \mathrm{~cm})$ tears to control rotator cuff tendons using microarrays. ${ }^{154}$ The results confirmed many previous studies, such as significant changes in extracellular matrix remodeling gene expression. Perhaps more important, analysis of the microarray data showed clear demarcations in gene expression patterns between the 3 different groups, indicating significant differences in the injury response between small and large tears.

\section{The Tendon Sheath and Adhesions}

A complication associated with tendon injuries is formation of adhesions between the tendon and the surrounding sheath or other tissues that limits range of motion. ${ }^{155,156}$ Cellular continuity between the tendon and surrounding tissue often occurs following injury as cells proliferate from the tendon and surrounding tissue to form the initial fibrous repair tissue. However, these cellular continuities must be resolved to allow the tendon to move freely and without limiting the range of motion. Nominally, these cellular continuities are resolved during healing and can be aided by early movement of the healing tendon and by non-steroidal antiinflammatory drug treatment. ${ }^{157,158}$ Failure to resolve the cellular continuities appears to lead to adhesion formation. Given the nature of the adhesions, the pathological mechanism leading to adhesion formation could be failure to slow cell proliferation during the repair phase, failure to stop production of predominant type III collagen fibrous tissue, failure to produce sufficient levels of extracellular matrix remodeling enzymes, or a combination of these processes. ${ }^{151}$ Additional research is needed to understand the etiology of adhesion formation and for improving methods to prevent adhesion formation.

\section{Healing at the Enthesis and Myotendinous Junction}

Tendons and ligaments are connected to bone through a specialized fibrocartilage and calcified fibrocartilage structure called the enthesis. ${ }^{159-162}$ Tendons connect to muscle at 
myotendinous junctions in which the tendon collagen fibrils interact with the sarcolemma of the muscle to allow force transmission. ${ }^{163}$ Despite the efficiency with which mechanical forces are transmitted through the enthesis and myotendinous junction, these junctions are mechanical weak points and sites of degenerative changes. Ruptures at myotendinous junctions appear to heal well and are often treated non-surgically. ${ }^{164}$ In contrast, healing of ruptured entheses is more problematic and typically the normal structure of the enthesis is not rejuvenated. Instead, in the repaired tendon-bone junction, the tendon and bone are joined by fibrocartilage. ${ }^{165,166}$

\section{Current Research Areas}

There is yet no gold-standard animal model for studying tendon repair, which makes comparison of gene expression and other data between models and species difficult. Complete and partial transection of the mouse Achilles tendon may be the best model to study the basic molecular and cellular events associated with tendon healing. The mouse Achilles tendon model allows for partial or complete transection, for no or simple suture repair, as well as testing of biomaterials and grafts. The mouse allows for use of genetically modified animals to directly assess gene functions on tendon healing, and healing can be measured using molecular, histological, and mechanical methods. ${ }^{167-173}$ However, any conclusion drawn from mouse Achilles tendon studies would need to be confirmed using clinical samples as there are clear differences in healing potentials between different tendons and species.

Research to improve tendon and ligament healing, improve healing at the enthesis or myotendinous junction, and that will prevent or minimize adhesions is ongoing. ${ }^{136,174,175}$ Efforts are focused on manipulating inflammation, ${ }^{158,176-180}$ using growth factors to control cell fates, ${ }^{33,181}$ altering extracellular matrix reorganization, ${ }^{182,183}$ and development of grafting materials. ${ }^{184}$ Another concept being explored is to recreate a healing environment that 
recapitulates that which occurs during fetal development in order to promote scarless wound healing. ${ }^{185}$

\section{E. Summary}

Multiple factors such as genetic predisposition, comorbidities, anatomy, proper and prompt diagnosis, treatment type (conservative or surgical), and patient compliance all contribute to the challenges associated with effectively treating fifth metatarsal injury, Charcot neuropathic osteoarthropathy, and arthrodesis. Even though these conditions have been extensively studied, successfully healing these conditions is still difficult. Research suggests that effective treatment begins with rapid and accurate diagnosis of the condition which is best completed using advancing imaging such as MRI. The stage of the condition, patient risk factors, and comorbidities dictate whether conservative treatment or surgical intervention is necessary. Conservative treatment often leads to re-fracture, nonunion, or secondary complications like ulceration or infection. Failed conservative treatment eventually leads to surgical intervention. Surgical intervention can include internal fixation, external fixation, bone grafts, orthobiologics, adjuvants, or a combination of these methods, which each have their drawbacks including pin migration, heterotopic ossification, or hardware failure. Despite these disadvantages, conservative, and surgical treatment can be successful. However, additional randomized controlled trials applying new or improved methods needs to be conducted in order to justify their use on bone, ligament, and tendon related injuries in the future.

\section{F. References}

1. De Boer AS, Schepers T, Panneman MJ, Van Beeck EF, Van Lieshout EM. Health care consumption and costs due to foot and ankle injuries in the Netherlands, 1986-2010. BMC musculoskeletal disorders. 2014;15:128. 
2. Einhorn TA, Gerstenfeld LC. Fracture healing: mechanisms and interventions. Nat Rev Rheumatol. 2015;11(1):45-54.

3. Gomez-Barrena E, Rosset P, Lozano D, Stanovici J, Ermthaller C, Gerbhard F. Bone fracture healing: cell therapy in delayed unions and nonunions. Bone. 2015;70:93-101.

4. Begkas D, Katsenis D, Pastroudis A. Management of aseptic non-unions of the distal third of the tibial diaphysis using static interlocking intramedullary nailing. Med Glas (Zenica). 2014;11(1):159-164.

5. Assal M, Stern R. Realignment and extended fusion with use of a medial column screw for midfoot deformities secondary to diabetic neuropathy. The Journal of bone and joint surgery. American volume. 2009;91(4):812-820.

6. Pacicca DM, Patel $\mathrm{N}$, Lee $\mathrm{C}$, et al. Expression of angiogenic factors during distraction osteogenesis. Bone. 2003;33(6):889-898.

7. Phillips AM. Overview of the fracture healing cascade. Injury. 2005;36 Suppl 3:S5-7.

8. Stoffel K, Engler H, Kuster M, Riesen W. Changes in biochemical markers after lower limb fractures. Clin Chem. 2007;53(1):131-134.

9. Chantelau EA, Grutzner G. Is the Eichenholtz classification still valid for the diabetic Charcot foot? Swiss Med Wkly. 2014;144:w13948.

10. Dennis SC, Berkland CJ, Bonewald LF, Detamore MS. Endochondral ossification for enhancing bone regeneration: converging native extracellular matrix biomaterials and developmental engineering in vivo. Tissue Eng Part B Rev. 2015;21(3):247-266.

11. Lin HN, Cottrell J, O'Connor JP. Variation in lipid mediator and cytokine levels during mouse femur fracture healing. Journal of orthopaedic research : official publication of the Orthopaedic Research Society. 2016:n/a-n/a.

12. Schlundt C, El Khassawna T, Serra A, et al. Macrophages in bone fracture healing: Their essential role in endochondral ossification. Bone. 2015.

13. Colnot $C$. Skeletal cell fate decisions within periosteum and bone marrow during bone regeneration. J Bone Miner Res. 2009;24(2):274-282.

14. Vortkamp A, Pathi S, Peretti GM, Caruso EM, Zaleske DJ, Tabin CJ. Recapitulation of signals regulating embryonic bone formation during postnatal growth and in fracture repair. Mech Dev. 1998;71(1-2):65-76.

15. Mackie EJ, Ahmed YA, Tatarczuch L, Chen KS, Mirams M. Endochondral ossification: how cartilage is converted into bone in the developing skeleton. The international journal of biochemistry \& cell biology. 2008;40(1):46-62.

16. Marsell R, Einhorn TA. The biology of fracture healing. Injury. 2011;42(6):551-555.

17. Sfeir C, Ho, L., Doll, B. A., Azari, K. and Hollinger, J.O. Fracture Repair. In: Lieberman JRaF, G. E., ed. Bone Regeneration and Repair. Totowa, NJ: Humana Press Inc.; 2005:21-44.

18. Reinholt FP, Hultenby K, Oldberg A, Heinegard D. Osteopontin--a possible anchor of osteoclasts to bone. Proceedings of the National Academy of Sciences of the United States of America. 1990;87(12):4473-4475.

19. Clarke B. Normal bone anatomy and physiology. Clin J Am Soc Nephrol. 2008;3 Suppl 3:S131139.

20. Hadjidakis DJ, Androulakis, II. Bone remodeling. Ann N Y Acad Sci. 2006;1092:385-396.

21. Kalfas IH. Principles of bone healing. Neurosurg Focus. 2001;10(4):E1.

22. Gougoulias N, Lampridis V. Midfoot arthrodesis. Foot Ankle Surg. 2016;22(1):17-25.

23. Rabinovich RV, Haleem AM, Rozbruch SR. Complex ankle arthrodesis: Review of the literature. World J Orthop. 2015;6(8):602-613.

24. Hardy MA, Logan DB. Principles of arthrodesis and advances in fixation for the adult acquired flatfoot. Clin Podiatr Med Surg. 2007;24(4):789-813, x. 
25. Saltzman CL, Kadoko RG, Suh JS. Treatment of isolated ankle osteoarthritis with arthrodesis or the total ankle replacement: a comparison of early outcomes. Clin Orthop Surg. 2010;2(1):1-7.

26. Terrell RD, Montgomery SR, Pannell WC, et al. Comparison of practice patterns in total ankle replacement and ankle fusion in the United States. Foot \& ankle international. 2013;34(11):1486-1492.

27. Xiaobing Y, Dewei, Z., Weiming, W. Evaluation of Clinical Effect of Ankle Arthrodesis and Total Ankle Arthroplasty for End-stage Ankle Arthritis. Clinical Research on Foot \& Ankle. 2014;2(2).

28. Hayden RJ, Jebson PJ. Wrist arthrodesis. Hand Clin. 2005;21(4):631-640.

29. Dux K, Edgar, S., Blume, P. A Guide to the Triple Arthrodesis for Hindfoot Deformities. Podiatry Today. Vol 25: HMP Communications, LLC; 2012.

30. Schuh R, Salzberger F, Wanivenhaus AH, Funovics PT, Windhager R, Trnka HJ. Kinematic changes in patients with double arthrodesis of the hindfoot for realignment of planovalgus deformity. Journal of orthopaedic research : official publication of the Orthopaedic Research Society. 2013;31(4):517-524.

31. Capobianco R, Cher D, Group SS. Safety and effectiveness of minimally invasive sacroiliac joint fusion in women with persistent post-partum posterior pelvic girdle pain: 12-month outcomes from a prospective, multi-center trial. Springerplus. 2015;4:570.

32. Rutherford EE, Tarplett L, Davies EM, Harley JM, King LJ. Lumbar spine fusion and stabilization: hardware, techniques, and imaging appearances. Radiographics. 2007;27(6):1737-1749.

33. Akyol E, Hindocha S, Khan WS. Use of stem cells and growth factors in rotator cuff tendon repair. Current stem cell research \& therapy. 2014;10(1):5-10.

34. Weiss HR, Goodall D. Rate of complications in scoliosis surgery - a systematic review of the Pub Med literature. Scoliosis. 2008;3:9.

35. Kovack TJ, Jacob PB, Mighell MA. Elbow arthrodesis: a novel technique and review of the literature. Orthopedics. 2014;37(5):313-319.

36. Schafroth MU, Blokzijl RJ, Haverkamp D, Maas M, Marti RK. The long-term fate of the hip arthrodesis: does it remain a valid procedure for selected cases in the 21st century? Int Orthop. 2010;34(6):805-810.

37. Bonasia DE, Dettoni F, Femino JE, Phisitkul P, Germano M, Amendola A. Total ankle replacement: why, when and how? lowa Orthop J. 2010;30:119-130.

38. AOFAS. Position Statement: The Use of Total Ankle Replacement for the Treatment of Arthritic Conditions of the Ankle. Rosemont, IL2014.

39. Lawrence SJ, Botte MJ. Jones' fractures and related fractures of the proximal fifth metatarsal. Foot Ankle. 1993;14(6):358-365.

40. Richli WR, Rosenthal DI. Avulsion fracture of the fifth metatarsal: experimental study of pathomechanics. AJR Am J Roentgenol. 1984;143(4):889-891.

41. Burge R, Dawson-Hughes B, Solomon DH, Wong JB, King A, Tosteson A. Incidence and economic burden of osteoporosis-related fractures in the United States, 2005-2025. J Bone Miner Res. 2007;22(3):465-475.

42. Raghavan $\mathrm{P}$, Christofides E. Role of teriparatide in accelerating metatarsal stress fracture healing: a case series and review of literature. Clin Med Insights Endocrinol Diabetes. 2012;5:3945.

43. Urteaga AJ, Lynch M. Fractures of the central metatarsals. Clin Podiatr Med Surg. 1995;12(4):759-772.

44. Fazzalari NL. Bone fracture and bone fracture repair. Osteoporos Int. 2011;22(6):2003-2006.

45. Kidd LJ, Stephens AS, Kuliwaba JS, Fazzalari NL, Wu AC, Forwood MR. Temporal pattern of gene expression and histology of stress fracture healing. Bone. 2010;46(2):369-378. 
46. Hatch RL, Alsobrook JA, Clugston JR. Diagnosis and management of metatarsal fractures. Am Fam Physician. 2007;76(6):817-826.

47. Petrisor BA, Ekrol I, Court-Brown C. The epidemiology of metatarsal fractures. Foot \& ankle international. 2006;27(3):172-174.

48. Petrisor BA, Poolman R, Koval K, Tornetta P, 3rd, Bhandari M. Management of displaced ankle fractures. J Orthop Trauma. 2006;20(7):515-518.

49. Rammelt S, Heineck J, Zwipp H. Metatarsal fractures. Injury. 2004;35 Suppl 2:SB77-86.

50. Strayer SM, Reece SG, Petrizzi MJ. Fractures of the proximal fifth metatarsal. Am Fam Physician. 1999;59(9):2516-2522.

51. Shereff MJ, Sobel MA, Kummer FJ. The stability of fixation of first metatarsal osteotomies. Foot Ankle. 1991;11(4):208-211.

52. Shereff MJ, Yang QM, Kummer FJ, Frey CC, Greenidge N. Vascular anatomy of the fifth metatarsal. Foot Ankle. 1991;11(6):350-353.

53. Smith JW, Arnoczky SP, Hersh A. The intraosseous blood supply of the fifth metatarsal: implications for proximal fracture healing. Foot Ankle. 1992;13(3):143-152.

54. Tahririan MA, Momeni A, Moayednia A, Yousefi E. Designing a prognostic scoring system for predicting the outcomes of proximal fifth metatarsal fractures at 20 weeks. Iran J Med Sci. 2015;40(2):104-109.

55. Theodorou DJ, Theodorou SJ, Kakitsubata Y, Botte MJ, Resnick D. Fractures of proximal portion of fifth metatarsal bone: anatomic and imaging evidence of a pathogenesis of avulsion of the plantar aponeurosis and the short peroneal muscle tendon. Radiology. 2003;226(3):857-865.

56. Bigsby E, Halliday R, Middleton RG, Case R, Harries W. Functional outcome of fifth metatarsal fractures. Injury. 2014;45(12):2009-2012.

57. Hanft JR, Goggin JP, Landsman A, Surprenant M. The role of combined magnetic field bone growth stimulation as an adjunct in the treatment of neuroarthropathy/Charcot joint: an expanded pilot study. J Foot Ankle Surg. 1998;37(6):510-515; discussion 550-511.

58. Mehlhorn AT, Zwingmann J, Hirschmuller A, Sudkamp NP, Schmal H. Radiographic classification for fractures of the fifth metatarsal base. Skeletal Radiol. 2014;43(4):467-474.

59. Quill GE, Jr. Fractures of the proximal fifth metatarsal. Orthop Clin North Am. 1995;26(2):353361.

60. Glasgow MT, Naranja RJ, Jr., Glasgow SG, Torg JS. Analysis of failed surgical management of fractures of the base of the fifth metatarsal distal to the tuberosity: the Jones fracture. Foot \& ankle international. 1996;17(8):449-457.

61. Husain ZS, DeFronzo DJ. Relative stability of tension band versus two-cortex screw fixation for treating fifth metatarsal base avulsion fractures. J Foot Ankle Surg. 2000;39(2):89-95.

62. Husain ZS, DeFronzo DJ. A comparison of bicortical and intramedullary screw fixations of Jones' fractures. J Foot Ankle Surg. 2002;41(3):146-153.

63. Lui TH. Lateral foot pain following open reduction and internal fixation of the fracture of the fifth metatarsal tubercle: treated by arthroscopic arthrolysis and endoscopic tenolysis. BMJ Case Rep. 2014;2014.

64. Mahajan V, Chung HW, Suh JS. Fractures of the proximal fifth metatarsal: percutaneous bicortical fixation. Clin Orthop Surg. 2011;3(2):140-146.

65. Weel $\mathrm{H}$, Mallee $\mathrm{WH}$, van Dijk CN, et al. The effect of concentrated bone marrow aspirate in operative treatment of fifth metatarsal stress fractures; a double-blind randomized controlled trial. BMC musculoskeletal disorders. 2015;16:211.

66. Wright RW, Fischer DA, Shively RA, Heidt RS, Jr., Nuber GW. Refracture of proximal fifth metatarsal (Jones) fracture after intramedullary screw fixation in athletes. The American journal of sports medicine. 2000;28(5):732-736. 
67. Nunley JA. Fractures of the base of the fifth metatarsal: the Jones fracture. Orthop Clin North Am. 2001;32(1):171-180.

68. Fernandez Fairen M, Guillen J, Busto JM, Roura J. Fractures of the fifth metatarsal in basketball players. Knee Surg Sports Traumatol Arthrosc. 1999;7(6):373-377.

69. Mologne TS, Lundeen JM, Clapper MF, O'Brien TJ. Early screw fixation versus casting in the treatment of acute Jones fractures. The American journal of sports medicine. 2005;33(7):970975.

70. Roche AJ, Calder JD. Treatment and return to sport following a Jones fracture of the fifth metatarsal: a systematic review. Knee Surg Sports Traumatol Arthrosc. 2013;21(6):1307-1315.

71. Yates J, Feeley I, Sasikumar S, Rattan G, Hannigan A, Sheehan E. Jones fracture of the fifth metatarsal: Is operative intervention justified? A systematic review of the literature and metaanalysis of results. Foot (Edinb). 2015;25(4):251-257.

72. Dameron TB, Jr. Fractures and anatomical variations of the proximal portion of the fifth metatarsal. The Journal of bone and joint surgery. American volume. 1975;57(6):788-792.

73. DeLee JC, Evans JP, Julian J. Stress fracture of the fifth metatarsal. The American journal of sports medicine. 1983;11(5):349-353.

74. Torg JS, Balduini FC, Zelko RR, Pavlov H, Peff TC, Das M. Fractures of the base of the fifth metatarsal distal to the tuberosity. Classification and guidelines for non-surgical and surgical management. The Journal of bone and joint surgery. American volume. 1984;66(2):209-214.

75. Zwitser EW, Breederveld RS. Fractures of the fifth metatarsal; diagnosis and treatment. Injury. 2010;41(6):555-562.

76. Klenerman L. The Charcot joint in diabetes. Diabet Med. 1996;13 Suppl 1:S52-54.

77. Sinha S, Munichoodappa CS, Kozak GP. Neuro-arthropathy (Charcot joints) in diabetes mellitus (clinical study of 101 cases). Medicine (Baltimore). 1972;51(3):191-210.

78. van der Ven A, Chapman CB, Bowker JH. Charcot neuroarthropathy of the foot and ankle. The Journal of the American Academy of Orthopaedic Surgeons. 2009;17(9):562-571.

79. Gouveri E, Papanas N. Charcot osteoarthropathy in diabetes: A brief review with an emphasis on clinical practice. World J Diabetes. 2011;2(5):59-65.

80. Rajbhandari SM, Jenkins RC, Davies C, Tesfaye S. Charcot neuroarthropathy in diabetes mellitus. Diabetologia. 2002;45(8):1085-1096.

81. Tesfaye S, Boulton AJ, Dyck PJ, et al. Diabetic neuropathies: update on definitions, diagnostic criteria, estimation of severity, and treatments. Diabetes Care. 2010;33(10):2285-2293.

82. Schade VL, Andersen CA. A literature-based guide to the conservative and surgical management of the acute Charcot foot and ankle. Diabet Foot Ankle. 2015;6:26627.

83. Schlossbauer T, Mioc T, Sommerey S, Kessler SB, Reiser MF, Pfeifer KJ. Magnetic resonance imaging in early stage charcot arthropathy: correlation of imaging findings and clinical symptoms. Eur J Med Res. 2008;13(9):409-414.

84. Chantelau E. The perils of procrastination: effects of early vs. delayed detection and treatment of incipient Charcot fracture. Diabet Med. 2005;22(12):1707-1712.

85. Chantelau E, Poll LW. Evaluation of the diabetic charcot foot by MR imaging or plain radiography--an observational study. Exp Clin Endocrinol Diabetes. 2006;114(8):428-431.

86. Chantelau E, Richter A, Schmidt-Grigoriadis P, Scherbaum WA. The diabetic charcot foot: MRI discloses bone stress injury as trigger mechanism of neuroarthropathy. Exp Clin Endocrinol Diabetes. 2006;114(3):118-123.

87. Pakarinen TK, Laine HJ, Honkonen SE, Peltonen J, Oksala H, Lahtela J. Charcot arthropathy of the diabetic foot. Current concepts and review of 36 cases. Scand J Surg. 2002;91(2):195-201.

88. Schoots IG, Slim FJ, Busch-Westbroek TE, Maas M. Neuro-osteoarthropathy of the footradiologist: friend or foe? Semin Musculoskelet Radiol. 2010;14(3):365-376. 
89. Yu GV, Hudson JR. Evaluation and treatment of stage 0 Charcot's neuroarthropathy of the foot and ankle. J Am Podiatr Med Assoc. 2002;92(4):210-220.

90. Zampa V, Bargellini I, Rizzo L, et al. Role of dynamic MRI in the follow-up of acute Charcot foot in patients with diabetes mellitus. Skeletal Radiol. 2011;40(8):991-999.

91. Armstrong DG, Peters EJ. Charcot's arthropathy of the foot. J Am Podiatr Med Assoc. 2002;92(7):390-394.

92. Perrin BM, Gardner MJ, Suhaimi A, Murphy D. Charcot osteoarthropathy of the foot. Aust Fam Physician. 2010;39(3):117-119.

93. Salo PT, Theriault E, Wiley RG. Selective ablation of rat knee joint innervation with injected immunotoxin: a potential new model for the study of neuropathic arthritis. Journal of orthopaedic research : official publication of the Orthopaedic Research Society. 1997;15(4):622628.

94. Tan AL, Greenstein A, Jarrett SJ, McGonagle D. Acute neuropathic joint disease: a medical emergency? Diabetes Care. 2005;28(12):2962-2964.

95. Caputo GM, Ulbrecht J, Cavanagh PR, Juliano P. The Charcot foot in diabetes: six key points. Am Fam Physician. 1998;57(11):2705-2710.

96. Giurini JM, Chrzan JS, Gibbons GW, Habershaw GM. Charcot's disease in diabetic patients. Correct diagnosis can prevent progressive deformity. Postgrad Med. 1991;89(4):163-169.

97. Shibata T, Tada K, Hashizume C. The results of arthrodesis of the ankle for leprotic neuroarthropathy. The Journal of bone and joint surgery. American volume. 1990;72(5):749-756.

98. Sinacore DR, Withrington NC. Recognition and management of acute neuropathic (Charcot) arthropathies of the foot and ankle. J Orthop Sports Phys Ther. 1999;29(12):736-746.

99. Rogers LC, Frykberg RG, Armstrong DG, et al. The Charcot foot in diabetes. J Am Podiatr Med Assoc. 2011;101(5):437-446.

100. Pinzur MS, Lio T, Posner M. Treatment of Eichenholtz stage I Charcot foot arthropathy with a weightbearing total contact cast. Foot \& ankle international. 2006;27(5):324-329.

101. Pinzur MS, Shields N, Trepman E, Dawson P, Evans A. Current practice patterns in the treatment of Charcot foot. Foot \& ankle international. 2000;21(11):916-920.

102. Armstrong DG, Todd WF, Lavery LA, Harkless LB, Bushman TR. The natural history of acute Charcot's arthropathy in a diabetic foot specialty clinic. J Am Podiatr Med Assoc. 1997;87(6):272278.

103. Pinzur M. Surgical versus accommodative treatment for Charcot arthropathy of the midfoot. Foot \& ankle international. 2004;25(8):545-549.

104. Sommer TC, Lee TH. Charcot foot: the diagnostic dilemma. Am Fam Physician. 2001;64(9):15911598.

105. Hastings MK, Sinacore DR, Fielder FA, Johnson JE. Bone mineral density during total contact cast immobilization for a patient with neuropathic (Charcot) arthropathy. Phys Ther. 2005;85(3):249256.

106. Richard JL, Almasri M, Schuldiner S. Treatment of acute Charcot foot with bisphosphonates: a systematic review of the literature. Diabetologia. 2012;55(5):1258-1264.

107. Lee L, Blume PA, Sumpio B. Charcot joint disease in diabetes mellitus. Ann Vasc Surg. 2003;17(5):571-580.

108. Simon SR, Tejwani SG, Wilson DL, Santner TJ, Denniston NL. Arthrodesis as an early alternative to nonoperative management of charcot arthropathy of the diabetic foot. The Journal of bone and joint surgery. American volume. 2000;82-A(7):939-950.

109. Sella EJ, Barrette C. Staging of Charcot neuroarthropathy along the medial column of the foot in the diabetic patient. J Foot Ankle Surg. 1999;38(1):34-40. 
110. Stapleton JJ, Zgonis T. Surgical reconstruction of the diabetic Charcot foot: internal, external or combined fixation? Clin Podiatr Med Surg. 2012;29(3):425-433.

111. Zgonis T, Roukis TS, Lamm BM. Charcot foot and ankle reconstruction: current thinking and surgical approaches. Clin Podiatr Med Surg. 2007;24(3):505-517, ix.

112. Zgonis T, Stapleton JJ, Jeffries LC, Girard-Powell VA, Foster LJ. Surgical treatment of Charcot neuropathy. AORN J. 2008;87(5):971-986; quiz 987-990.

113. Sammarco VJ. Superconstructs in the treatment of charcot foot deformity: plantar plating, locked plating, and axial screw fixation. Foot Ankle Clin. 2009;14(3):393-407.

114. Sammarco VJ, Sammarco GJ, Walker EW, Jr., Guiao RP. Midtarsal arthrodesis in the treatment of Charcot midfoot arthropathy. The Journal of bone and joint surgery. American volume. 2009;91(1):80-91.

115. Grant WP, Garcia-Lavin SE, Sabo RT, Tam HS, Jerlin E. A retrospective analysis of 50 consecutive Charcot diabetic salvage reconstructions. J Foot Ankle Surg. 2009;48(1):30-38.

116. Pappalardo J, Fitzgerald R. Utilization of advanced modalities in the management of diabetic Charcot neuroarthropathy. J Diabetes Sci Technol. 2010;4(5):1114-1120.

117. Camathias $\mathrm{C}$, Valderrabano $\mathrm{V}$, Oberli $\mathrm{H}$. Routine pin tract care in external fixation is unnecessary: a randomised, prospective, blinded controlled study. Injury. 2012;43(11):1969-1973.

118. Wiewiorski $M$, Valderrabano $\mathrm{V}$. Intramedullary fixation of the medial column of the foot with a solid bolt in Charcot midfoot arthropathy: a case report. J Foot Ankle Surg. 2012;51(3):379-381.

119. Wiewiorski M, Yasui T, Miska M, Frigg A, Valderrabano V. Solid bolt fixation of the medial column in Charcot midfoot arthropathy. J Foot Ankle Surg. 2013;52(1):88-94.

120. Belczyk R, Ramanujam CL, Capobianco CM, Zgonis T. Combined midfoot arthrodesis, muscle flap coverage, and circular external fixation for the chronic ulcerated Charcot deformity. Foot Ankle Spec. 2010;3(1):40-44.

121. Capobianco CM, Ramanujam CL, Zgonis T. Charcot foot reconstruction with combined internal and external fixation: case report. J Orthop Surg Res. 2010;5:7.

122. Wukich DK, Belczyk RJ, Burns PR, Frykberg RG. Complications encountered with circular ring fixation in persons with diabetes mellitus. Foot \& ankle international. 2008;29(10):994-1000.

123. Baumhauer J, Pinzur MS, Donahue R, Beasley W, DiGiovanni C. Site selection and pain outcome after autologous bone graft harvest. Foot \& ankle international. 2014;35(2):104-107.

124. Deresh GM, Cohen M. Reconstruction of the diabetic Charcot foot incorporating bone grafts. J Foot Ankle Surg. 1996;35(5):474-488.

125. Fitzgibbons TC, Hawks MA, McMullen ST, Inda DJ. Bone grafting in surgery about the foot and ankle: indications and techniques. The Journal of the American Academy of Orthopaedic Surgeons. 2011;19(2):112-120.

126. Roukis T. A simple technique for harvesting autogenous bone grafts from the calcaneus. Foot \& ankle international. 2006;27(11):998-999.

127. Roukis TS, Hyer CF, Philbin TM, Berlet GC, Lee TH. Complications associated with autogenous bone marrow aspirate harvest from the lower extremity: an observational cohort study. $J$ Foot Ankle Surg. 2009;48(6):668-671.

128. Roukis TS, Zgonis T, Tiernan B. Autologous platelet-rich plasma for wound and osseous healing: a review of the literature and commercially available products. Adv Ther. 2006;23(2):218-237.

129. Pinzur MS. Use of platelet-rich concentrate and bone marrow aspirate in high-risk patients with Charcot arthropathy of the foot. Foot \& ankle international. 2009;30(2):124-127.

130. Bem R, Jirkovska A, Fejfarova V, Skibova J, Jude EB. Intranasal calcitonin in the treatment of acute Charcot neuroosteoarthropathy: a randomized controlled trial. Diabetes Care. 2006;29(6):1392-1394. 
131. Fourman MS, Borst EW, Bogner E, Rozbruch SR, Fragomen AT. Recombinant human BMP-2 increases the incidence and rate of healing in complex ankle arthrodesis. Clinical orthopaedics and related research. 2014;472(2):732-739.

132. Liporace FA, Bibbo C, Azad V, Koerner J, Lin SS. Bioadjuvants for complex ankle and hindfoot reconstruction. Foot Ankle Clin. 2007;12(1):75-106.

133. Anderson $\mathrm{CL}$, Whitaker $\mathrm{MC}$. Heterotopic ossification associated with recombinant human bone morphogenetic protein-2 (infuse) in posterolateral lumbar spine fusion: a case report. Spine (Phila Pa 1976). 2012;37(8):E502-506.

134. Burkus JK, Dryer RF, Peloza JH. Retrograde ejaculation following single-level anterior lumbar surgery with or without recombinant human bone morphogenetic protein-2 in 5 randomized controlled trials: clinical article. J Neurosurg Spine. 2013;18(2):112-121.

135. Slater GL, Sayres SC, O'Malley MJ. Anterior ankle arthrodesis. World J Orthop. 2014;5(1):1-5.

136. Loiselle AE, Kelly M, Hammert WC. Biological Augmentation of Flexor Tendon Repair: A Challenging Cellular Landscape. The Journal of hand surgery. 2016;41(1):144-149; quiz 149.

137. Soldatis JJ, Goodfellow DB, Wilber JH. End-to-end operative repair of Achilles tendon rupture. The American journal of sports medicine. 1997;25(1):90-95.

138. Kannus $\mathrm{P}$, Jozsa L. Histopathological changes preceding spontaneous rupture of a tendon. A controlled study of 891 patients. The Journal of bone and joint surgery. American volume. 1991;73(10):1507-1525.

139. Bestwick CS, Maffulli N. Reactive oxygen species and tendinopathy: do they matter? British journal of sports medicine. 2004;38(6):672-674.

140. Zhang J, Wang JH. Production of PGE(2) increases in tendons subjected to repetitive mechanical loading and induces differentiation of tendon stem cells into non-tenocytes. Journal of orthopaedic research : official publication of the Orthopaedic Research Society. 2010;28(2):198203.

141. Li Z, Yang G, Khan M, Stone D, Woo SL, Wang JH. Inflammatory response of human tendon fibroblasts to cyclic mechanical stretching. The American journal of sports medicine. 2004;32(2):435-440.

142. Flick J, Devkota A, Tsuzaki M, Almekinders L, Weinhold P. Cyclic loading alters biomechanical properties and secretion of PGE2 and NO from tendon explants. Clinical biomechanics (Bristol, Avon). 2006;21(1):99-106.

143. Tsuzaki M, Guyton G, Garrett W, et al. IL-1 beta induces COX2, MMP-1, -3 and -13, ADAMTS-4, IL-1 beta and IL-6 in human tendon cells. Journal of orthopaedic research : official publication of the Orthopaedic Research Society. 2003;21(2):256-264.

144. Bidell MR, Lodise TP. Fluoroquinolone-Associated Tendinopathy: Does Levofloxacin Pose the Greatest Risk? Pharmacotherapy. 2016.

145. Arabyat RM, Raisch DW, McKoy JM, Bennett CL. Fluoroquinolone-associated tendon-rupture: a summary of reports in the Food and Drug Administration's adverse event reporting system. Expert opinion on drug safety. 2015;14(11):1653-1660.

146. Corps AN, Harrall RL, Curry VA, Fenwick SA, Hazleman BL, Riley GP. Ciprofloxacin enhances the stimulation of matrix metalloproteinase 3 expression by interleukin-1beta in human tendonderived cells. A potential mechanism of fluoroquinolone-induced tendinopathy. Arthritis and rheumatism. 2002;46(11):3034-3040.

147. Mobasheri A, Shakibaei M. Is tendinitis an inflammatory disease initiated and driven by proinflammatory cytokines such as interleukin 1beta? Histol Histopathol. 2013;28(8):955-964.

148. Andersson C, Odensten M, Good L, Gillquist J. Surgical or non-surgical treatment of acute rupture of the anterior cruciate ligament. A randomized study with long-term follow-up. The Journal of bone and joint surgery. American volume. 1989;71(7):965-974. 
149. Nagineni CN, Amiel D, Green MH, Berchuck M, Akeson WH. Characterization of the intrinsic properties of the anterior cruciate and medial collateral ligament cells: an in vitro cell culture study. Journal of orthopaedic research : official publication of the Orthopaedic Research Society. 1992;10(4):465-475.

150. Woo SL, Vogrin TM, Abramowitch SD. Healing and repair of ligament injuries in the knee. The Journal of the American Academy of Orthopaedic Surgeons. 2000;8(6):364-372.

151. Juneja SC, Schwarz EM, O'Keefe RJ, Awad HA. Cellular and molecular factors in flexor tendon repair and adhesions: a histological and gene expression analysis. Connective tissue research. 2013;54(3):218-226.

152. Manning CN, Havlioglu N, Knutsen E, et al. The early inflammatory response after flexor tendon healing: a gene expression and histological analysis. Journal of orthopaedic research : official publication of the Orthopaedic Research Society. 2014;32(5):645-652.

153. Brophy RH, Tycksen ED, Sandell LJ, Rai MF. Changes in Transcriptome-Wide Gene Expression of Anterior Cruciate Ligament Tears Based on Time From Injury. The American journal of sports medicine. 2016.

154. Chaudhury S, Xia Z, Thakkar D, Hakimi O, Carr AJ. Gene expression profiles of changes underlying different-sized human rotator cuff tendon tears. Journal of shoulder and elbow surgery / American Shoulder and Elbow Surgeons ... [et al.]. 2016.

155. Lilly SI, Messer TM. Complications after treatment of flexor tendon injuries. The Journal of the American Academy of Orthopaedic Surgeons. 2006;14(7):387-396.

156. Dy CJ, Hernandez-Soria A, Ma Y, Roberts TR, Daluiski A. Complications after flexor tendon repair: a systematic review and meta-analysis. The Journal of hand surgery. 2012;37(3):543-551.e541.

157. Hasslund S, Jacobson JA, Dadali $\mathrm{T}$, et al. Adhesions in a murine flexor tendon graft model: autograft versus allograft reconstruction. Journal of orthopaedic research : official publication of the Orthopaedic Research Society. 2008;26(6):824-833.

158. Tan V, Nourbakhsh A, Capo J, Cottrell JA, Meyenhofer M, O'Connor JP. Effects of nonsteroidal anti-inflammatory drugs on flexor tendon adhesion. The Journal of hand surgery. 2010;35(6):941-947.

159. Thomopoulos S, Genin GM, Galatz LM. The development and morphogenesis of the tendon-tobone insertion - what development can teach us about healing. Journal of musculoskeletal \& neuronal interactions. 2010;10(1):35-45.

160. Benjamin M, Evans EJ, Copp L. The histology of tendon attachments to bone in man. Journal of anatomy. 1986;149:89-100.

161. Doschak MR, Zernicke RF. Structure, function and adaptation of bone-tendon and boneligament complexes. Journal of musculoskeletal \& neuronal interactions. 2005;5(1):35-40.

162. Benjamin M, McGonagle D. Entheses: tendon and ligament attachment sites. Scandinavian journal of medicine \& science in sports. 2009;19(4):520-527.

163. Trotter JA. Structure-function considerations of muscle-tendon junctions. Comp Biochem Physiol A Mol Integr Physiol. 2002;133(4):1127-1133.

164. Ahmad J, Repka M, Raikin SM. Treatment of myotendinous Achilles ruptures. Foot \& ankle international. 2013;34(8):1074-1078.

165. Liu SH, Panossian V, al-Shaikh R, et al. Morphology and matrix composition during early tendon to bone healing. Clinical orthopaedics and related research. 1997(339):253-260.

166. Thomopoulos S, Williams GR, Soslowsky L. Tendon to bone healing: differences in biomechanical, structural, and compositional properties due to a range of activity levels. Journal of biomechanical engineering. 2003;125(1):106-113.

167. de la Durantaye M, Piette AB, van Rooijen N, Frenette J. Macrophage depletion reduces cell proliferation and extracellular matrix accumulation but increases the ultimate tensile strength of 
injured Achilles tendons. Journal of orthopaedic research : official publication of the Orthopaedic Research Society. 2014;32(2):279-285.

168. Freedman BR, Sarver JJ, Buckley MR, Voleti PB, Soslowsky L. Biomechanical and structural response of healing Achilles tendon to fatigue loading following acute injury. Journal of biomechanics. 2014;47(9):2028-2034.

169. Godbout C, Bilodeau R, Van Rooijen N, Bouchard P, Frenette J. Transient neutropenia increases macrophage accumulation and cell proliferation but does not improve repair following intratendinous rupture of Achilles tendon. Journal of orthopaedic research : official publication of the Orthopaedic Research Society. 2010;28(8):1084-1091.

170. Xia W, Wang Y, Appleyard RC, Smythe GA, Murrell GA. Spontaneous recovery of injured Achilles tendon in inducible nitric oxide synthase gene knockout mice. Inflammation research : official journal of the European Histamine Research Society ... [et al.]. 2006;55(1):40-45.

171. Chhabra A, Tsou D, Clark RT, Gaschen V, Hunziker EB, Mikic B. GDF-5 deficiency in mice delays Achilles tendon healing. Journal of orthopaedic research : official publication of the Orthopaedic Research Society. 2003;21(5):826-835.

172. Palmes D, Spiegel HU, Schneider TO, et al. Achilles tendon healing: long-term biomechanical effects of postoperative mobilization and immobilization in a new mouse model. Journal of orthopaedic research : official publication of the Orthopaedic Research Society. 2002;20(5):939946.

173. Juneja SC, Veillette C. Defects in tendon, ligament, and enthesis in response to genetic alterations in key proteoglycans and glycoproteins: a review. Arthritis. 2013;2013:154812.

174. Branford OA, Klass BR, Grobbelaar AO, Rolfe KJ. The growth factors involved in flexor tendon repair and adhesion formation. The Journal of hand surgery, European volume. 2014;39(1):6070.

175. Rawson S, Cartmell S, Wong J. Suture techniques for tendon repair; a comparative review. Muscles, ligaments and tendons journal. 2013;3(3):220-228.

176. Dimmen S. Effects of Cox inhibitors on bone and tendon healing. Acta orthopaedica. Supplementum. 2011;82(342):1-22.

177. Dimmen S, Nordsletten L, Engebretsen L, Steen H, Madsen JE. The effect of parecoxib and indometacin on tendon-to-bone healing in a bone tunnel: an experimental study in rats. The Journal of bone and joint surgery. British volume. 2009;91(2):259-263.

178. Carlstedt CA, Madsen K, Wredmark T. The influence of indomethacin on tendon healing. A biomechanical and biochemical study. Archives of orthopaedic and trauma surgery. 1986;105(6):332-336.

179. Forslund C, Bylander B, Aspenberg P. Indomethacin and celecoxib improve tendon healing in rats. Acta orthopaedica Scandinavica. 2003;74(4):465-469.

180. Dakin SG, Dudhia J, Smith RK. Resolving an inflammatory concept: the importance of inflammation and resolution in tendinopathy. Veterinary immunology and immunopathology. 2014;158(3-4):121-127.

181. Bissell L, Tibrewal S, Sahni V, Khan WS. Growth factors and platelet rich plasma in anterior cruciate ligament reconstruction. Current stem cell research \& therapy. 2014;10(1):19-25.

182. Farhat YM, Al-Maliki AA, Easa A, O'Keefe RJ, Schwarz EM, Awad HA. TGF-beta1 Suppresses Plasmin and MMP Activity in Flexor Tendon Cells via PAI-1: Implications for Scarless Flexor Tendon Repair. Journal of cellular physiology. 2015;230(2):318-326.

183. Davis ME, Gumucio JP, Sugg KB, Bedi A, Mendias CL. MMP inhibition as a potential method to augment the healing of skeletal muscle and tendon extracellular matrix. Journal of applied physiology (Bethesda, Md. : 1985). 2013;115(6):884-891. 
184. Wong R, Alam N, McGrouther AD, Wong JK. Tendon grafts: their natural history, biology and future development. The Journal of hand surgery, European volume. 2015;40(7):669-681.

185. Galatz LM, Gerstenfeld L, Heber-Katz E, Rodeo SA. Tendon regeneration and scar formation: The concept of scarless healing. Journal of orthopaedic research : official publication of the Orthopaedic Research Society. 2015;33(6):823-831.

\section{FIGURE LEGENDS}

Figure 1. Representation of fracture repair including growth factors and cytokines at each stage.

From Sfeir C, Ho, L., Doll, B. A., Azari, K. and Hollinger, J.O. Fracture Repair. In: Lieberman

JRaF, G. E., ed. Bone Regeneration and Repair. Totowa, NJ: Humana Press Inc.; 2005:21-44, with permission.

Figure 2. Hallux valgus deformity (a) corrected with (b) arthrodesis of tarsometatarsal joints (Lapidus procedure). From Gougoulias N, Lampridis V. Midfoot arthrodesis. Foot Ankle Surg. 2016;22(1):17-25, with permission. 


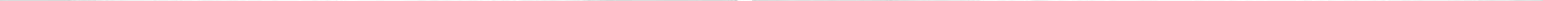

